
H A R V A R D
B U S I N E S S
S C H O O L

\title{
Does Product Market Competition Lead Firms to Decentralize?
}

\author{
Nicholas Bloom \\ Raffaella Sadun \\ John Van Reenen
}

\section{Working Paper}

10-052

This paper is part of the SCIFI-GLOW Collaborative Project supported by the European Commission's Seventh Research Framework Programme, Contract number SSH7-CT-2008-217436.

Copyright ( 2010 by Nicholas Bloom, Raffaella Sadun, and John Van Reenen

Working papers are in draft form. This working paper is distributed for purposes of comment and discussion only. It may not be reproduced without permission of the copyright holder. Copies of working papers are available from the author. 
DOES PRODUCT MARKET COMPETITION LEAD FIRMS TO DECENTRALIZE?

\author{
Nicholas Bloom \\ Department of Economics \\ Stanford University \\ 579 Serra Mall \\ CA 94305 \\ nbloom@stanford.edu \\ 6507253786 or 6504457179 \\ Raffaella Sadun \\ Graduate School of Business \\ Harvard University \\ Soldiers Field \\ Boston, MA 02163 \\ rsadun@hbs.edu \\ 6174956190 \\ John Van Reenen (Corresponding Author) \\ Department of Economics \\ London School of Economics \\ Houghton Street \\ London, WC2A 2AE \\ j.vanreenen@1se.ac.uk \\ +442079557284
}




\section{Does Product Market Competition Lead Firms to Decentralize?}

\section{Nicholas Bloom, Raffaella Sadun and John Van Reenen*}

There is a widespread sense that over the last two decades firms have been decentralizing decisions to employees further down the managerial hierarchy. Economists have developed a range of theories to account for delegation, but there is less empirical evidence, especially across countries. This has limited the ability to understand the phenomenon of decentralization. To address the empirical lacuna we have developed a research program to measure the internal organization of firms - including their decentralization decisions - across a large range of industries and countries.

In this paper we investigate whether greater product market competition increases decentralization. For example, tougher competition may make local manager's information more valuable, as delays to decisions become more costly. Since globalization and liberalization have increased the competitiveness of product markets, one explanation for the trend towards decentralization could be increased competition. Of course there are a range of other factors that may also be at play, including human capital (Eve Caroli and John Van Reenen, 2001), information and communication technology (Timothy Bresnahan, Erik Brynjolfsson and Lorin Hitt, 2002), culture (Bloom, Sadun and Van Reenen, 2009) and industrial composition.

To tackle these issues we collected detailed information on the internal organization of firms across nations. The few datasets that exist are either from a single industry ${ }^{1}$ or (at best) across many firms in a single country ${ }^{2}$. We analyze data on almost 4,000 firms across twelve countries in Europe, North America and Asia. We find that competition does indeed seem to foster greater decentralization. 


\section{SOME THEORIES}

A number of papers such as Philippe Aghion and Jean Tirole (1997), George Baker, Robert Gibbons and Kevin Murphy (1999), Canice Prendergast (2002) and Oliver Hart and John Moore (2004), consider the delegation decision in the context of an information-based approach. For example, Acemoglu et al. (2007) examine a model where a firm faces a choice over whether to adopt a new technology. The principal is the Central Head Quarters (CHQ) and the agent is the plant manager. The CHQ has a greater interest in maximizing the firm's value than the manager, but the manager has greater local private knowledge than the CHQ. Characteristics of the environment that increase: (i) the value of local information; and (ii) the congruence of incentives between the CHQ and plant manager, will increase decentralization.

How does competition affect this trade off? There are several reasons to expect the relationship between competition and decentralization to be positive. First, if competition reduces the agency problem then delegation is more likely as incentives are more aligned. This could be because (i) managers work harder to avoid bankruptcy; (ii) competition fosters a greater sensitivity of profits to relative differences in managerial effort or (iii) if there are more firms then it is easier to implement yardstick competition.

Ricardo Alonso, Wouter Dessein and Niko Matouschek (2009) emphasize the incentive to centralize to overcome within-firm spillovers. For example, when a firm has two plants selling separate substitutable products, local plant managers will tend to set a price that is too low from the firm's perspective, as the cannibalization effect is not internalized. Tougher competition will make the loss from this cannibalization smaller though, as price cost margins fall. So long as there is some incentive to delegate because of local information advantages the incentive to decentralize rises as competition increases. 
There are also competitive forces working against decentralization. On the incentives/agency side, greater competition may actually reduce managerial effort, as the smaller mark-ups mean that the incentive to exert greater managerial effort to raise firm profitability is blunted. This is a variety of the well-known "Schumpeterian" effect on innovation - lower quasirents reduce incentives to take activities that lower marginal costs. On the information side, if competition increases the number of firms, then there will be more public information, so in the Acemoglu et al (2007) model the principal can learn from observing other firms and take more decisions directly.

Ultimately, the effect of competition on decentralization is an empirical issue. To look at this question using our organizational data, we estimate models of the form:

$$
D_{i j c}=\beta C O M P_{i j c}+\delta^{\prime} x_{i j c}+u_{i j}
$$

where $C O M P$ is an indicator of product market competition for plant $i$ in industry $j$ in country $c$, $x$ is a vector of other controls (including country and industry dummies).

\section{DATA}

We collected data on almost 4,000 medium sized (100 to 5,000 employees) manufacturing firms across a dozen countries which we briefly describe here.

II.A Measuring Decentralization: We investigated the decentralization of decision making from the CEO to the plant-manager. The plant-manager is the most senior person at the factory level, so their autonomy from the CEO, who is typically based in the corporate head quarters, is a natural measure decentralization. To quantify this we measured decentralization along four dimensions. First, how much capital investment could a plant manager undertake without prior authorization from the corporate headquarters? Second, how much control does the plant manager have in hiring a new full-time permanent shopfloor employee? Third, how much control 
does the plant manager have over introducing new products? Fourth how much control does the manger have over sales and marketing decisions? These last three measures were scaled from a score of 1 , defined as all decisions taken at the corporate headquarters, to a 5 defined as all decisions taken at the plant (decentralization). Since the scaling may vary across all these questions, we converted all four measures to z-scores (mean zero, unit standard deviation) and in our baseline took the average of the four z-scores. We also collected information on management practices (following Bloom and Van Reenen, 2007), the proportion of employees with college degrees, average hours worked and the gender and age breakdown. From the sample database we also have information for most firms on accounting variables like sales and capital stock.

II.B Collecting Accurate Responses: To obtain truthful responses we took a number of steps. First, the survey was conducted by telephone without telling the managers they were being scored on organizational practices. This enabled scoring to be based on the interviewer's evaluation of the firm's actual practices, rather than their aspirations, the manager's perceptions or the interviewer's impressions. To run this "blind" scoring we used open questions (i.e. "To hire a full-time permanent shop-floor worker what agreement would your plant need from corporate headquarters"?), rather than closed questions (i.e. "Can you hire workers without authority from corporate headquarters?"[yes/no]). Following the initial question the discussion would continue until the interviewer can make an accurate assessment of the firm's typical practices. For example, if the plant manager responded "It is my decision, but I need sign-off from corporate HQ." the interviewer would ask "How often would sign-off typically be given?" and "Can you give me any examples when that sign-off has not been given". Second, the interviewers were not told anything about the firm's financial information or performance in advance of the interview. Since the firms (median size 270 employees) are too small to attract 
much media coverage, this should mean the interviewers had no preconceptions about the firms before they interviewed them. Third, each interviewer ran 85 interviews on average, allowing us to remove interviewer fixed effects. Fourth, the survey instrument was targeted at plant managers, who are typically senior enough to have an overview of organizational practices but not so senior as to be detached from day-to-day operations. Fifth, we collected a detailed set of information on the interview process itself (e.g. local time of day), the manager (e.g. nationality), and on the interviewer. These survey metrics are used as "noise controls" to help reduce residual variation. Finally, to maximize comparability every interviewer also had the same initial three days of interview training to ensure a common interpretation of the scoring grid. The team operated from one location and interviewers surveyed firms across multiple countries, so for example, a French speaking interviewer would interview firms in France, the UK and the US.

II.C. Descriptive Statistics: Intriguingly, we found that firms developing countries (Brazil, China and India), tended to be the most centralized, with almost all major decisions taken by the owners in the corporate headquarters (see Bloom, Sadun and Van Reenen, 2009). Japanese firms were also relatively centralized. In contrast, firms in Anglo-Saxon and Scandinavian countries (Canada, Germany, Sweden, UK and US) were relatively decentralized. The rest of Europe (e.g. France, Italy, and Poland) tended to be in the middle of the decentralization ranking.

\section{RESULTS}

Table 1 examines the association between decentralization and different measures of product market competition, revealing a robustly positive relationship. We use three different proxies for product market competition following Steve Nickell (1996) and Philippe Aghion et al. (2005). 


\section{TABLE 1 - COMPETITION AND DECENTRALIZATION}

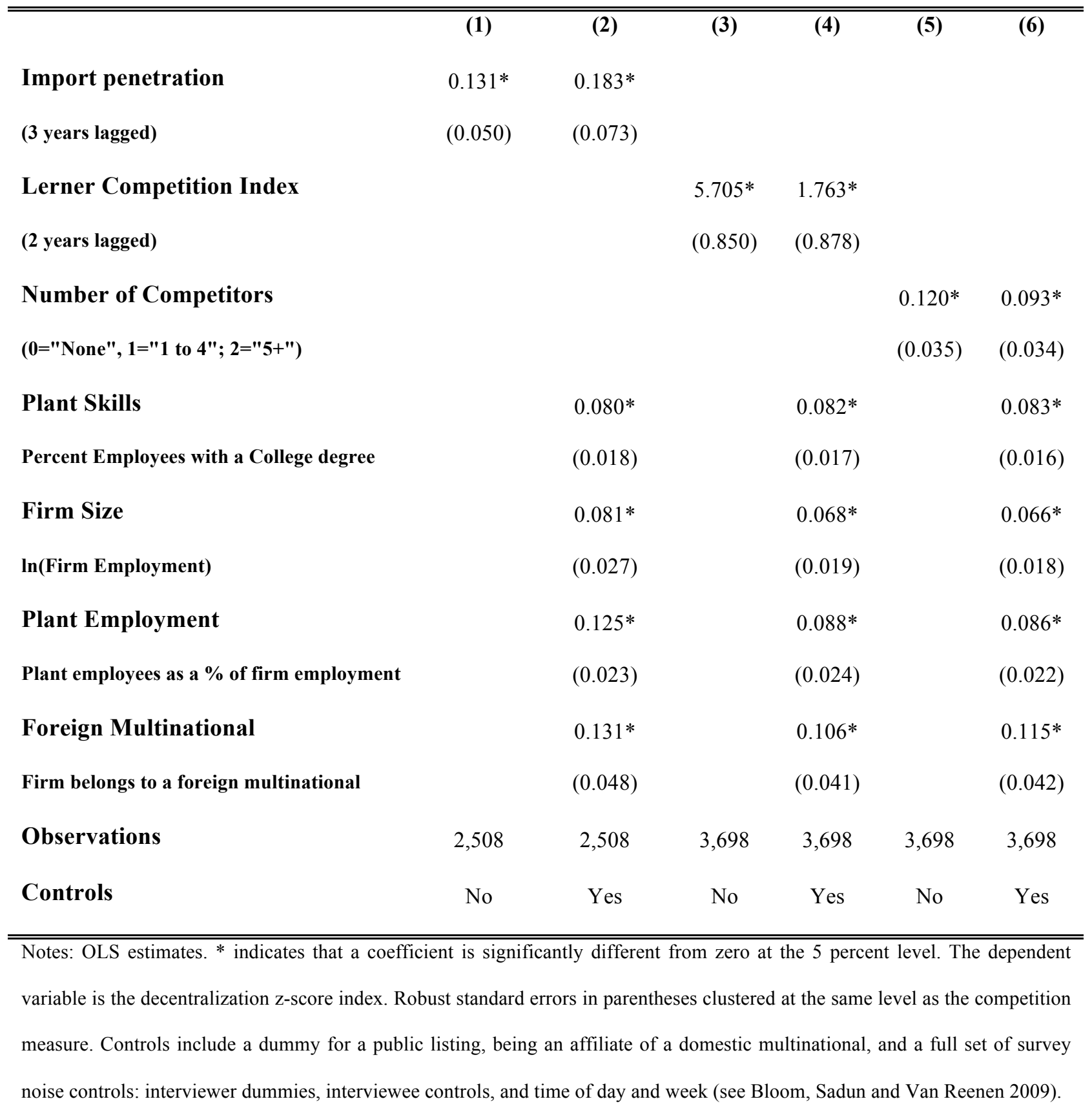

The first measure is the degree of import penetration in the country by two-digit industry measured as the share of total imports over domestic production. This is constructed for the 5year period 1999-2003 to remove any potential contemporaneous feedback. The second is the 
country by three digit industry Lerner index of competition, which is (1 - profits/sales), calculated as the average across the entire firm level database (excluding the firms in the survey). Again, this is constructed for the 5-year period 2000-2004 to remove any potential contemporaneous feedback ${ }^{3}$. The third measure of competition is the manager's response to the survey question on the number of competitors a firm faces, valued zero for "no competitors", one for "between one and five competitors", and two for "5 or more competitors".

Reassuringly, whichever measure of competition we use, we still find a very strong and robust relationship between more competition and greater levels of decentralization. In column (1), higher import competition is positively and significantly associated with greater decentralization. In column (2) we include controls for skills, size, multinational status, country and three-digit industry dummies and find this result appears to be robust to these additional explanatory variables. In terms of these other covariates, we find that larger firms and plants, especially those belonging to foreign multinationals are more likely to delegate, potentially because of greater operational complexity and the importance of local knowledge. Plants with higher levels of human capital are more likely to be autonomous, presumably because more educated managers are better able to effectively run their own plants. Finally, in other recent work we have found that plants located in regions with higher trust and less hierarchical religions are also likely to be autonomous (see Bloom, Sadun and Van Reenen 2009, for more analysis of these cultural issues) ${ }^{4}$.

In columns (3) and (4) we run an identical specification, but instead using the lagged industry-level (inverse) Lerner index as an alternative measure of competition. We again find a significant and positive association between competition and decentralization without and with the full set of controls. Finally, in columns (5) and (6) we run another similar specification using 
the plant manager's own self reported measure of the perceived number of competitors. Again we find a positive and significant association with and without the full set of controls. This reveals that the more rivals a firm perceives it faces, the more decentralized it appears to be.

In summary, we find a highly significant and robust relationship between more competition and greater firm-level decentralization. The magnitude of these competition effects are also of economic as well as statistical significance. For example, in column (6) increasing the number of competitors from zero to five is associated with an increase in the decentralization index of about 0.2 , equivalent to going from a relatively decentralized European country like Germany to a very decentralized country like the US.

\section{CONCLUSIONS}

We have addressed the question of whether competition fosters delegation by assembling a new dataset on about 4,000 firms across 12 countries that measures the delegation of authority from Central Head Quarters to local plant managers. We find that competition is associated with a greater degree of delegation. This suggests that one of the reasons for the move towards decentralization over time in the developed countries may be due to increasing competition, possibly arising from more globalized product markets. It also implies that a reason for the greater centralization in less developed countries may be due to lower competitive intensity.

\section{References}

Acemoglu Daron, Philippe Aghion, Claire Lelarge, John Van Reenen, and Fabrizio Zilibotti. 2007. "Technology, Information and the Decentralization of the Firm". Quarterly Journal of Economics, 122(4): 1759-1799. 
Aghion, Philippe, Nick Bloom, Richard Blundell, Rachel Griffith and Peter Howitt. 2005.

“Competition and Innovation: An Inverted U Relationship”. Quarterly Journal of Economics, 120(2): 701-728.

Aghion, Philippe, and Jean Tirole. 1997. "Formal and Real Authority in Organizations". Journal of Political Economy, 105(1): 1-29.

Alonso, Ricardo, Wouter Dessein and Niko Matouschek (2009) "Competition and Decentralization" University of Columbia mimeo

Baker, George, Robert Gibbons, and Kevin Murphy. 1999. "Informal Authority in Organizations”. Journal of Law, Economics, and Organization, 15(1): 56-73.

Bloom, Nicholas, and John Van Reenen. 2007. "Measuring and Explaining Management Practices across Firms and Countries". Quarterly Journal of Economics, 122(4): 1341-1408.

Bloom, Nicholas, Raffaella Sadun, and John Van Reenen. 2009. “The Organization of Firms across Countries”. Centre for Economic Performance Discussion Paper No. 937

Bresnahan, Timothy, Erik Brynjolfsson, and Lorin Hitt. 2002. "Information Technology, Workplace Organization and the Demand for Skilled Labor: Firm-level Evidence”. Quarterly Journal of Economics, 117(1): 339-376.

Caroli, Eve, and John Van Reenen. 2001. "Skill Biased Organizational Change". Quarterly Journal of Economics, 116(4): 1449-1492.

Colombo, Massimo, and Marco Delmastro. 2004. "Delegation of Authority in Business Organizations: An Empirical Test”. Journal of Industrial Economics, 52(1), 53-80.

Garicano, Luis, and Thomas Hubbard. 2007. "Managerial Leverage is Limited by the Extent of the Market: Hierarchies, Specialization, and the Utilization of Lawyers' Human Capital". Journal of Law and Economics: 50(1), 1-43. 
Guadalupe, Maria and Julie Wulf. 2007. "The Flattening Firm and Product Market Competition”. Centre for Economic Policy and Research Discussion Paper 7253.

Hart, Oliver and John Moore. 2005. “On the Design of Hierarchies: Coordination versus Specialization”. Journal of Political Economy: 113(4), 675-702.

Kastl, Jakub, David Martimort, and Salvatore Piccolo. 2008. "Delegation and R\&D Incentives: Theory and Evidence from Italy". Centre for Studies in Economics and Finance Working Paper 192.

Prendergast, Canice. 2002. "The Tenuous Trade-Off between Risk and Incentives". Journal of Political Economy: 110(5), 1071-102.

\footnotetext{
* Nicholas Bloom, Department of Economics, Stanford University, 578 Serra Mall, CA 94350, nbloom@stanford.edu, 6507253786 and CEP and NBER. Raffaella Sadun, Graduate School of Business, Harvard University, Soldiers Field, Boston, MA 02163, rsadun@hbs.edu, 6174956190 and CEP. John Van Reenen, Department of Economics, London School of Economics, Houghton Street, London, WC2A 2AE, j.vanreenen@1se.ac.uk, +44 2079557284 and CEP, CEPR and NBER.

${ }^{1}$ For example, Luis Garicano and Tom Hubbard (2007) on legal services.

${ }^{2}$ See, for example, Daron Acemoglu et al. (2007) for France and the UK; Massimo Colombo and Marco Delmastro (2004) and Jakub Kastl, David Martimort and Salvatore Piccolo (2008) for Italy; and Maria Guadalupe and Julie Wulf (2007) for the US.

${ }^{3}$ The difference in timing between the import penetration measure and the Lerner index is due to the fact that the accounting data is available until 2004 but the OECD import competition data is available only until 2003.

${ }^{4}$ All competition results in Table 1 are robust to the inclusion of trust and hierarchical religion controls. The coefficients (standard errors) of the competition variables are $0.154(0.067), 2.920(1.119)$ and $0.099(0.031)$ in columns (2), (4) and (6) respectively. Similarly, the results are robust to the inclusion of a summary management measure (see Bloom and Van Reenen 2007 for details). In this specification the coefficients (standard errors) of the competition variables are $0.173(0.073), 1.591(0.872)$ and $0.067(0.034)$ in columns (2), (4) and (6) respectively.
} 